\title{
Contribuição à filogenia de abelhas Melipona com uso de sequências parciais da região ITS1 do nrDNA
}

\author{
Contribution to the phylogeny of Melipona bees based \\ on partial sequences from ITS1 nrDNA region
}

Isac Gabriel Abrahão Bomfim ${ }^{[a]}$, Breno Magalhães Freitas ${ }^{[b]}$, Giorgio Cristino Venturieri[c], Daniel Macedo de Melo Jorge ${ }^{[]]}$, Marina Duarte Pinto Lobo ${ }^{[e]}$, Davi Coe Torres ${ }^{[[]}$, Thalles Barbosa Grangeiro ${ }^{[g]}$

[a] Zootecnista, doutor em Zootecnia, professor do Instituto Centro de Ensino Tecnológico (CENTEC/FATEC), Quixeramobim, CE - Brasil, e-mail: isacbomfim@yahoo.com.br

[b] Engenheiro agrônomo, Ph.D. em Abelhas e Polinização, professor associado da Universidade Federal do Ceará (UFC), Fortaleza, CE - Brasil, e-mail: freitas@ufc.br

[c] Engenheiro agrônomo, doutor em Ecologia, pesquisador A da Empresa Brasileira de Pesquisa Agropecuária (Embrapa), Centro de Pesquisa Agroflorestal da Amazônia Oriental, Belém, PA - Brasil, e-mail: giorgio@cpatu.embrapa.br

[d] Biólogo, doutor em Genética, pós-doutor na University of Michigan, EUA, e-mail: danielmacedo.jorge@gmail.com

[e] Bióloga, doutoranda em Bioquímica, Universidade Federal do Ceará (UFC), Fortaleza, CE - Brasil, e-mail: marinadplobo@gmail.com

[f] Biólogo, Ph.D. em Ciências Biológicas, pós-doutor no Instituto Nacional de Câncer (INCA), Rio de Janeiro, RJ - Brasil, e-mail: torresdc@gmail.com

[g] Engenheiro agrônomo, doutor em Bioquímica, professor associado da Universidade Federal do Ceará (UFC), Fortaleza, CE - Brasil, e-mail: tbgrangeiro@gmail.com

\section{Resumo}

O objetivo deste estudo foi investigar, por meio de dados moleculares de sequências de DNA, as relações filogenéticas de abelhas indígenas sem ferrão do táxon Melipona nativas do Brasil. Procurou-se, assim, fornecer subsídios para facilitar uma futura revisão taxonômica sobre esse grupo de abelhas. Sequências parciais da região do espaçador transcrito interno I (ITS1) do DNA ribossômico nuclear (nrDNA) foram obtidas de espécimes de $M$. flavolineata, $M$. mondury e $M$. fasciculata, coletados em estados do Norte, Nordeste e Sudeste do Brasil. 0 alinhamento múltiplo das sequências geradas em conjunto com outras 25 do gênero Melipona, depositadas no GenBank ou publicadas em artigos científicos por outros autores, apresentou 141 caracteres alinhados, com uma distância genética média de 0,075 (Jukes-Cantor) entre todas as sequências estudadas do táxon Melipona. As árvores obtidas através dos métodos de Neighbor-Joining (NJ), Máxima Parcimônia (MP) e Máxima Verossimilhança (MV) apresentaram essencialmente a mesma topologia, que define três clados: (i) espécimes do subgênero Melipona s. str. (M. subnitida, M. quadrifasciata e M. mandacaia); (ii) espécimes do subgênero Melikerria (M. quinquefasciata e M. fasciculata); e (iii) espécimes do subgênero Michmelia (M. mondury, M. flavolineata e M. scutellaris). Os dados moleculares gerados no presente trabalho 
confirmam a organização taxonômica do gênero Melipona em pelo menos três subgêneros (Melipona, Melikerria e Michmelia), e demonstram a utilidade da sequência da região ITS1 do nrDNA para resolver relações de parentesco infragenéricas em Meliponina.

Palavras-chave: Biologia molecular. Sequenciamento automático. Reconstrução filogenética. Abelhas sem ferrão.

\section{Abstract}

The aim of this research was to investigate the phylogenetic relationships of Brazilian indigenous stingless bee species of the Melipona taxon using molecular data to contribute to future taxonomic revision of this group. Partial sequences of the ITS1 of nrDNA were obtained from specimens of M. flavolineata, M. mondury and M. fasciculata collected in states of the North, Northeast and Southeast regions of Brazil. Multiple alignment of the new generated sequences along with 25 Melipona sequences imported from GenBank or from available scientific literature, yielded 141 aligned sites, with an average genetic distance of 0.075 (Jukes-Cantor) among all Melipona sequences under study. Phylogenetic trees generated by Neighbor-Joining (NJ), Maximum Parsimony (MP) and Maximum Likelihood (ML) algorithms provided virtually the same topology and three clades were defined: (i) specimens belonging to the Melipona subgenus (M. subnitida, M. quadrifasciata and M. mandacaia); (ii) specimens of the Melikerria subgenus (M. quinquefasciata and M. fasciculate); and (iii) specimens of the Michmelia subgenus (M. mondury, M. flavolineata and M. scutellaris). The molecular data generated in this study support the taxonomic organization of the Melipona genus in at least three subgenera (Melipona, Melikerria and Michmelia) and demonstrate the importance of the molecular marker ITS1 to resolve infrageneric phylogenies in Meliponina.

Keywords: Molecular biology. Automated sequencing. Phylogenetic reconstruction. Stingless bees.

\section{Introdução}

Apesar da biologia de certas espécies de Melipona Illiger, 1806 (Apidae: Meliponina) (SILVEIRA et al., 2002) já estar bem documentada, muitos aspectos sistemáticos sobre este táxon ainda permanecem obscuros. Taxonomicamente o gênero é bastante uniforme. De fato, vários grupos de espécies são similares, muitas vezes diferindo, aparentemente, apenas em padrões de cores, o que faz com que muitos autores prefiram classificá-los como subespécies (VELTHUIS et al., 2003), assim subestimando a grande riqueza desse táxon (SILVEIRA et al., 2002; VELTHUIS et al., 2003). Outro problema que nos leva a subestimar sua riqueza é a existência de espécies crípticas (MICHENER, 2007), além do grande número de espécies ainda não propriamente reconhecidas, principalmente dentro da complexa fauna da região amazônica (MELO, 2003).
De acordo com a classificação proposta por Moure (1992), este táxon compreende cerca de 40 espécies distribuídas em quatro subgêneros: Melipona (Melipona s. str.) Illiger, 1806; Melipona (Michmelia) Moure, 1975; Melipona (Melikerria) Moure, 1992; Melipona (Eomelipona) Moure, 1992, os quais foram baseados totalmente em caracteres morfológicos e refletem as relações de similaridade e afinidade entre as espécies do gênero Melipona (SILVEIRA et al., 2002). Entretanto, Michener (2007) não reconhece nenhum destes subgêneros devido à grande similaridade morfológica existente entre eles.

Logo, para esclarecer essas questões taxonômicas seria de grande utilidade uma filogenia robusta desse táxon, baseada tanto em dados morfológicos quanto em dados moleculares (FERNANDES-SALOMÃO et al., 2005; RAMÍREZ et al., 2010; RASMUSSEN; CAMERON, 2010). A 
taxonomia tradicionalmente utilizada é a morfológica, mas o avanço da biologia molecular tem permitido que a aplicação de caracteres provenientes de ácidos nucleicos e proteínas ajudem na solução de diversos problemas outrora obscuros no campo da sistemática (JUDD et al., 2008; RAMÍREZ et al., 2010). 0 papel da sistemática é, portanto, além de realizar o trabalho tradicional da taxonomia, realizar o trabalho de organizar o conhecimento sobre a diversidade biológica a partir da relação de parentescos entre os grupos e do conhecimento da evolução das características morfológicas, comportamentais, ecológicas, fisiológicas, citogenéticas e moleculares dos grupos (MIYAKI et al., 2001).

A necessidade de marcadores filogenéticos do genoma nuclear para completar os crescentes dados de DNA mitocondrial levou ao reconhecimento da região ITS como uma nova escolha para os sistematas (JOBES; THIEN, 1997). Dentro dessa região encontra-se o espaçador transcrito interno1 (ITS1), que faz parte do locus do rDNA eucariótico e separa duas regiões funcionais: a $18 \mathrm{~S}$ rDNA e a 5,8S rDNA. Por ser o ITS1 um elemento não codificante de evolução relativamente rápida, se tornou bastante utilizado em reconstruções filogenéticas de táxons proximamente relacionados (ARMBRUSTER; KORTE, 2006). A região ITS1 do rDNA do táxon Melipona apresenta um grande potencial para estudos filogenéticos entre espécies (FERNANDES-SALOMÃO et al., 2002), como também pode ajudar a resolver dúvidas taxonômicas relacionadas aos subgêneros deste táxon (FERNANDES-SALOMÃO et al., 2005). Além disso, pode servir para avaliar variações intraespecíficas em populações de abelhas, como demonstrado para M. subnitida (CRUZ et al., 2006) e M. quinquefasciata (PEREIRA et al., 2009).

Estudos prévios conduzidos por Cruz et al. (2006) e Pereira et al. (2009) revelaram que o sequenciamento parcial da região 3' do ITS1 do nrDNA apresenta variabilidade nucleotídica suficiente para se estudar o táxon Melipona ao nível infragenérico. Assim, o presente trabalho propõe inferir as relações filogenéticas do táxon Melipona, analisadas pelo sequenciamento parcial da região ITS1 do DNA ribossômico nuclear, visando fornecer dados para facilitar uma futura revisão taxonômica sobre o gênero Melipona.

\section{Material e métodos}

\section{Material coletado e isolamento do DNA genômico}

As amostras de abelhas foram coletadas nas regiões Norte, Nordeste e Sudeste do Brasil, acondicionadas em tubos contendo etanol $100 \%$ e posteriormente levadas ao Laboratório de Genética Molecular (LGM) localizado na Universidade Federal do Ceará.

Espécies, origem geográfica, número de tombo na coleção de abelhas do Departamento de Zootecnia da Universidade Federal do Ceará, e número de depósito no GenBank das sequências de DNA das amostras em estudo estão descritos na Tabela 1.

O DNA genômico total foi extraído a partir de quatro mesossomas de cada amostra, através de um protocolo baseado no reagente brometo de cetil

Tabela 1 - Espécies analisadas no Laboratório de Genética Molecular (LGM) com seus respectivos subgêneros, locais de coleta e códigos de depósito

\begin{tabular}{|c|c|c|c|c|c|}
\hline Subgênero & Espécie & $\begin{array}{l}\text { Localidade } \\
\text { (Cidade/Estado) }\end{array}$ & $\begin{array}{l}\text { Coordenadas } \\
\text { Geográficas }\end{array}$ & $\mathrm{N}^{\circ}$ de tombo & $\begin{array}{l}\mathrm{N}^{\circ} \text { de acesso } \\
\text { no GenBank }\end{array}$ \\
\hline Melikerria & Melipona fasciculata Smith, 1858 & Belém/PA & $1^{\circ} 27^{\prime} 18^{\prime \prime} S, 48^{\circ} 30^{\prime} 08^{\prime \prime} \mathrm{W}$ & MGPA0108 & GU983042 \\
\hline Michmelia & Melipona flavolineata Friese, 1900 & Belém/PA & $1^{\circ} 27^{\prime} 18^{\prime \prime} S, 48^{\circ} 30^{\prime} 08^{\prime \prime} \mathrm{W}$ & MGPA0208 & GU983043 \\
\hline Michmelia & Melipona mondurySmith, 1863 & Rio Vermelho/MG & $18^{\circ} 16^{\prime} 40^{\prime \prime} \mathrm{S}, 43^{\circ} 00^{\prime} 28^{\prime \prime} \mathrm{W}$ & MGPA0308 & GU983044 \\
\hline Michmelia & Melipona mondury Smith, 1863 & Pacoti/CE & $4^{\circ} 13^{\prime} 28^{\prime \prime} S, 38^{\circ} 55^{\prime} 31^{\prime \prime} \mathrm{W}$ & MGPA0408 & GU983045 \\
\hline Michmelia & Melipona mondury Smith, 1863 & Guaramiranga/CE & $4^{\circ} 16^{\prime} 16^{\prime \prime} S, 38^{\circ} 56^{\prime} 46^{\prime \prime} \mathrm{W}$ & MGPA0508 & GU983046 \\
\hline- & Scaptotrigona sp. Lepeletier, 1836 & Maranguape/CE & $3^{\circ} 53^{\prime} 26^{\prime \prime} S, 38^{\circ} 40^{\prime} 54^{\prime \prime} \mathrm{W}$ & MGPA0608 & GU983047 \\
\hline
\end{tabular}

Fonte: Dados da pesquisa. 
trimetil lamônio - CTAB (FOSTER; TWELL, 1996), realizando as adaptações sugeridas por Cruz et al. (2006) e Pereira et al. (2009).

A concentração e a qualidade do DNA das amostras foram determinadas medindo-se a absorbância a $260 \eta \mathrm{m}\left(\mathrm{A}_{260}\right)$ e checando-se as preparações por eletroforese em gel de agarose $0,8 \%(\mathrm{~m} / \mathrm{v})$, de acordo com Sambrook e Russel (2001).

\section{Amplificação e sequenciamento de DNA}

0 fragmento de DNA correspondente à região ITS1 do nrDNA foi amplificado por reação em cadeia da polimerase (PCR - Polymerase Chain Reaction) utilizando os oligonucleotídeos ITS2 (5'-GCTGCGTTCTTCATCGATGC-3') e ITS5 (5'-GCAAGTAAAAGTCGTAACAAGG-3'), que são específicos às extremidades que flanqueiam a região ITS1 (BECERRA; VENABLE, 1999).

As reações de PCR foram realizadas num volume final de $25 \mu \mathrm{L}$ contendo 800 ng de DNA genômico, Tris- $\mathrm{HCl} 20 \mathrm{mM}$, pH 8,4, KCl 50 mM, $\mathrm{MgCl}_{2}$ 1,5 mM, $100 \mu \mathrm{M}$ de cada dNTP (dATP, dCTP, dGTP e dTTP), 5 pmoles de cada oligonucleotídeo (ITS2 e ITS5) e 0,5 unidades de Taq DNA polimerase. Além das amostras testadas na reação de PCR, foi utilizado um controle negativo, que continha água no lugar do DNA, e o restante dos componentes.

0 processo de amplificação foi conduzido em um termociclador programado para um passo inicial de desnaturação $\left(3 \mathrm{~min}\right.$ a $\left.95^{\circ} \mathrm{C}\right)$, seguido por 35 ciclos de $1 \mathrm{~min}$ a $95{ }^{\circ} \mathrm{C}, 1 \mathrm{~min}$ a $55^{\circ} \mathrm{C}$ (anelamento) e 2 min a $72{ }^{\circ} \mathrm{C}$ (extensão). 0 último ciclo foi seguido por uma incubação de $10 \mathrm{~min}$ a $72{ }^{\circ} \mathrm{C}$. As amostras foram então armazenadas a $4{ }^{\circ} \mathrm{C}$ até serem utilizadas. Os fragmentos amplificados foram analisados por eletroforese horizontal em gel de agarose 1,0\% (m/v), de acordo com Sambrook e Russel (2001). As reações de sequenciamento foram realizadas com o auxílio do DYEnamic ET Terminator Cycle Sequencing Kit, seguindo o protocolo fornecido pelo fabricante, e analisadas com o sequenciador automático MegaBACE 1000 (Amersham Biosciences Corp., Piscataway - NJ, EUA). Cada produto de PCR foi sequenciado oito vezes em apenas uma direção utilizando o iniciador ITS2.

\section{Análise das sequências}

As sequências geradas para cada amostra foram submetidas ao pacote de programas de montagem e obtenção de sequências consenso phred/phrap/ consed (EWING; GREEN, 1998; EWING et al., 1998; GORDON et al., 1998). As sequências consenso estabelecidas (phred $>20$ ) foram submetidas à busca por similaridade no GenBank (NCBI - National Center for Biotechnology Information) pela ferramenta BLASTn (Basic Local Alignment Search Tool) com o intuito de detectar possíveis contaminantes (ZHANG et al., 2000).

Posteriormente, realizou-se o alinhamento múltiplo das sequências geradas junto com outras 22 do gênero Melipona já depositas no GenBank, além de 03 (três) sequências publicadas por FernandesSalomão et al. (2005) (Tabela 2), totalizando 31 sequências estudadas, através do programa CLUSTAL W, versão 1.83, utilizando os parâmetros de alinhamento predefinido de gap-penalties (THOMPSON, 1997). A análise de composição nucleotídica e conteúdo $\mathrm{G}+\mathrm{C}$ foi realizada com auxílio do programa MEGA (Molecular Evolutionary Genetic Analysis), versão 4.0 (TAMURA et al., 2007).

\section{Análises dos agrupamentos taxonômicos}

0 primeiro teste realizado a partir do alinhamento múltiplo editado foi o teste do modelo, utilizando o Critério de Informação de Akaike (AIC Akaike Information Criterion) através do programa ModelTest, versão 3.7 (POSADA; CRANDALL, 1998). Este programa foi utilizado com o objetivo de verificar qual o modelo de substituição mais adequado aos dados obtidos. Para a construção de todos os cladogramas utilizou-se como grupo externo do táxon Melipona a espécie Scaptotrigona sp., que pertence ao mesmo gênero utilizado por Fernandes-Salomão et al. (2005) para análise da filogenia do mesmo táxon.

A análise filogenética por máxima parcimônia (MP) foi realizada com auxílio do programa PAUP* (Phylogenetic Analysis Using Parsimony), versão 4.0b10 (SWOFFORD, 1998), através de uma busca heurística com os seguintes parâmetros: adição aleatória de sequências com 1000 replicatas, mantendo-se para cada replicata as 10 árvores mais parcimoniosas e utilizando-se o algoritmo tree bisection-reconnection (TBR) branch-swapping, que 
Tabela 2 - Sequências da região ITS1 do nrDNA importadas do GenBank e obtidas de Fernandes-Salomão et al. (2005), que foram utilizadas para as análises filogenéticas no presente trabalho

\begin{tabular}{|c|c|c|c|}
\hline Subgênero & Espécie & Localidade & $\mathbf{N}^{\circ}$ de acesso no GenBank \\
\hline Melipona s. str. & Melipona subnitida & Quixadá/CE & DQ078726 \\
\hline Melipona s. str. & Melipona subnitida & Sousa/PB & DQ078727 \\
\hline Melipona s. str. & Melipona subnitida & Ocara/CE & DQ078728 \\
\hline Melipona s. str. & Melipona subnitida & Mossoró/RN & DQ078729 \\
\hline Melipona s. str. & Melipona subnitida & Russas/CE & DQ078730 \\
\hline Melipona s. str. & Melipona subnitida & Sobral/CE & DQ078731 \\
\hline Melipona s. str. & Melipona subnitida & Milhã/CE & DQ078732 \\
\hline Melipona s. str. & Melipona subnitida & Quixelô/CE & DQ078733 \\
\hline Melipona s. str. & Melipona subnitida & Aracati/CE & DQ078734 \\
\hline Melipona s. str. & Melipona subnitida & Aracoiaba/CE & DQ078735 \\
\hline Melipona s. str. & Melipona subnitida & João Câmara/RN & DQ078736 \\
\hline Melipona s. str. & Melipona subnitida & Chorozinho/CE & DQ078737 \\
\hline Melipona s. str. & Melipona subnitida & Araioses/MA & DQ078738 \\
\hline Melikerria & Melipona quinquefasciata & Crato/CE (Flona 1) & EU073753 \\
\hline Melikerria & Melipona quinquefasciata & Crato/CE (Flona 2) & EU073754 \\
\hline Melikerria & Melipona quinquefasciata & Crato/CE (Flona 3) & EU073755 \\
\hline Melikerria & Melipona quinquefasciata & Araripe/CE (Araripe 1) & EU073751 \\
\hline Melikerria & Melipona quinquefasciata & Araripe/CE (Araripe 3) & EU073752 \\
\hline Melikerria & Melipona quinquefasciata & São Benedito/CE & EU073758 \\
\hline Melikerria & Melipona quinquefasciata & Jardim/CE (Jardim 1)) & EU073756 \\
\hline Melikerria & Melipona quinquefasciata & Canto do Buriti/PI & EU073757 \\
\hline Melikerria & Melipona quinquefasciata & Luziânia/G0 & EU073759 \\
\hline Melipona s. str. & Melipona mandacaia & São R. Nonato/PI & * \\
\hline Melipona s. str. & Melipona quadrifasciata anthidioides & Viçosa/MG & * \\
\hline Michmelia & Melipona scutellaris & Lençóis/BA & * \\
\hline
\end{tabular}

Fonte: Dados da pesquisa.

promove rearranjos em uma dada árvore inicial e a melhor entre todas as construídas é escolhida. Os gaps, envolvendo dados de inserção e/ou deleção nucleotídica, foram considerados como dados perdidos.

As análises de máxima verossimilhança (MV) e de distância (Neighbor-joining - NJ) também foram realizadas usando o programa PAUP*, utilizando o modelo mais apropriado de acordo com teste do modelo descrito acima. Foram realizadas análises de bootstrap com 1000 replicações, que têm o intuito de testar a confiança nas topologias obtidas, em todos os métodos acima descritos.

\section{Resultados}

A análise dos produtos de PCR revelou diferenças entre o tamanho dos fragmentos amplificados para a região ITS1 do nrDNA. 0 tamanho do fragmento variou desde aproximadamente $1500 \mathrm{pb}$ (Scaptotrigona sp. e M. fasciculata) até próximo de 2000 pb (M. flavolineata; M. mondury - Rio Vermelho; M. mondury - Pacoti e M. mondury - Guaramiranga).

Devido a uma grande variação entre os tamanhos das sequências geradas e aquelas importadas do GenBank, foi necessário realizar um corte nas extremidades 5' e 3' do alinhamento primário com a finalidade de uniformizar o tamanho das sequências. Deste modo, o alinhamento múltiplo das 30 sequências do táxon Melipona estudadas apresentou 141 sítios, considerando 17 (12\%) sítios que correspondem a inserções/deleções (indels), introduzidos com o intuito de otimizar o alinhamento. Esses gaps foram excluídos para a análise e comparação das características do alinhamento com estudos prévios, como mostra a Tabela 3. 
Tabela 3 - Características do alinhamento das sequências parciais da região ITS1 de espécies do táxon Melipona do presente trabalho comparadas com sequências ITS1 dos estudos prévios de Cruz et al. (2006) e Pereira et al. (2009)

\begin{tabular}{lccc}
\hline Características do alinhamento & $\begin{array}{c}\text { Presente trabalho } \\
\text { (interespecíico/ } \\
\text { Gênero Melipona) }\end{array}$ & $\begin{array}{c}\text { Cruz et al. (2006) } \\
\text { (intraespecífico/Melipona } \\
\text { subnitida) }\end{array}$ & $\begin{array}{c}\text { Pereira et al. (2009) } \\
\text { (intraespecífico/ } \\
\text { Melipona quinquefasciata) }\end{array}$ \\
\hline $\mathrm{N}^{0}$ total de sítos alinhados & 141 & 654 & 499 \\
$\mathrm{~N}^{0}$ de sítios alinhados excluindo indels & 124 & 576 & 487 \\
$\mathrm{~N}^{0}$ de indels & $17(12 \%)$ & $78(11,9 \%)$ & $12(2,4 \%)$ \\
$\mathrm{N}^{0}$ de sítios conservados & $80(64,5 \%)$ & $437(75,9 \%)$ & $462(94,9 \%)$ \\
$\mathrm{N}^{0}$ de sítios variáveis & $44(35,5 \%)$ & $139(24,1 \%)$ & $25(5,1 \%)$ \\
$\mathrm{N}^{0}$ de sítios autopomórficos & $26(21 \%)$ & $104(18,1 \%)$ & $19(3,9 \%)$ \\
$\mathrm{N}^{0}$ de sítios informativos à parcimônia & $19(14,5 \%)$ & $35(6,1 \%)$ & $6(1,2 \%)$ \\
Diferença média entre o $\mathrm{n}^{0}$ de nucleotídeos & $8,5(7 \%)$ & $29(5,2 \%)$ & $7(1,4 \%)$ \\
(sequências comparadas par a par) & & & \\
\hline
\end{tabular}

Fonte: Dados da pesquisa.

0 conteúdo $\mathrm{G}+\mathrm{C}$ entre as amostras pertencentes ao táxon Melipona variou de 50,4 a 55,5\% em M. scutellaris e M. subnitida - Ocara, respectivamente, e apresentou um conteúdo G+C médio de 53,3\%. Entre as amostras extraídas no LGM, o conteúdo $\mathrm{G}+\mathrm{C}$ foi de 48,8\% em Scaptotrigona sp., 52,7\% em M. flavolineata, M. mondury - Rio Vermelho, M. mondury - Pacoti e M. mondury - Guaramiranga e 53,6\% em M. fascicutata.

Segundo o teste do modelo realizado pelo programa ModelTest (POSADA; CRANDALL, 1998), o modelo matemático de Jukes e Cantor (1969) foi o mais adequado para os dados estudados, modelo que é baseado na distribuição de Poisson e que leva em consideração substituições múltiplas e frequências de bases iguais (PEREIRA et al., 2001). A distância genética média entre todas as sequências parciais da região ITS1 do táxon Melipona foi de 0,075. Diferenças entre essas sequências, excluindo os sítios contendo indels, variaram de 0 a 32 nucleotídeos ( $0 \%$ a $26,5 \%)$, assim representando uma máxima divergência ao redor de $26,5 \%$.

As análises de máxima parcimônia (MP), máxima verossimilhança (MV) (Figura 1) e do agrupamento do vizinho mais próximo (NJ) (Figura 2), mostraram essencialmente a mesma topologia, com ligeiras variações na resolução dos ramos terminais e nos valores de bootstrap.

A análise de MP incluiu 19 sítios informativos à parcimônia. A árvore mais parcimoniosa apresentou 420 passos, com índice de consistência (CI - consistency index) de 0,963 e índice de retenção (RI - retention index) de 0,985. Um CI próximo a 1 implica uma baixa quantidade de homoplasias nos sítios analisados, assim como valores de RI próximos a 1 implicam que os sítios são bem informativos para a construção de árvores mais parcimoniosas (NEI; KUMAR, 2000; SCHNEIDER, 2007). Como todos os índices obtidos foram maiores que 0,963 , a topologia gerada através deste método (MP) se encontra bem consistente no presente trabalho.

Três grupos principais, sustentados por altos valores de bootstrap (>90\%), foram definidos nas árvores geradas: (i) espécimes do subgênero Melipona s. str. (M. subnitida, M. quadrifasciata e M. mandacaia); (ii) espécimes do subgênero Melikerria (M. quinquefasciata e M. fasciculata); e (iii) espécimes do subgênero Michmelia (M. mondury, M. flavolineata e M. scutellaris). Apesar dos dados gerados não permitirem a distinção de todas as espécies em estudos, observa-se uma distância genética substancial 


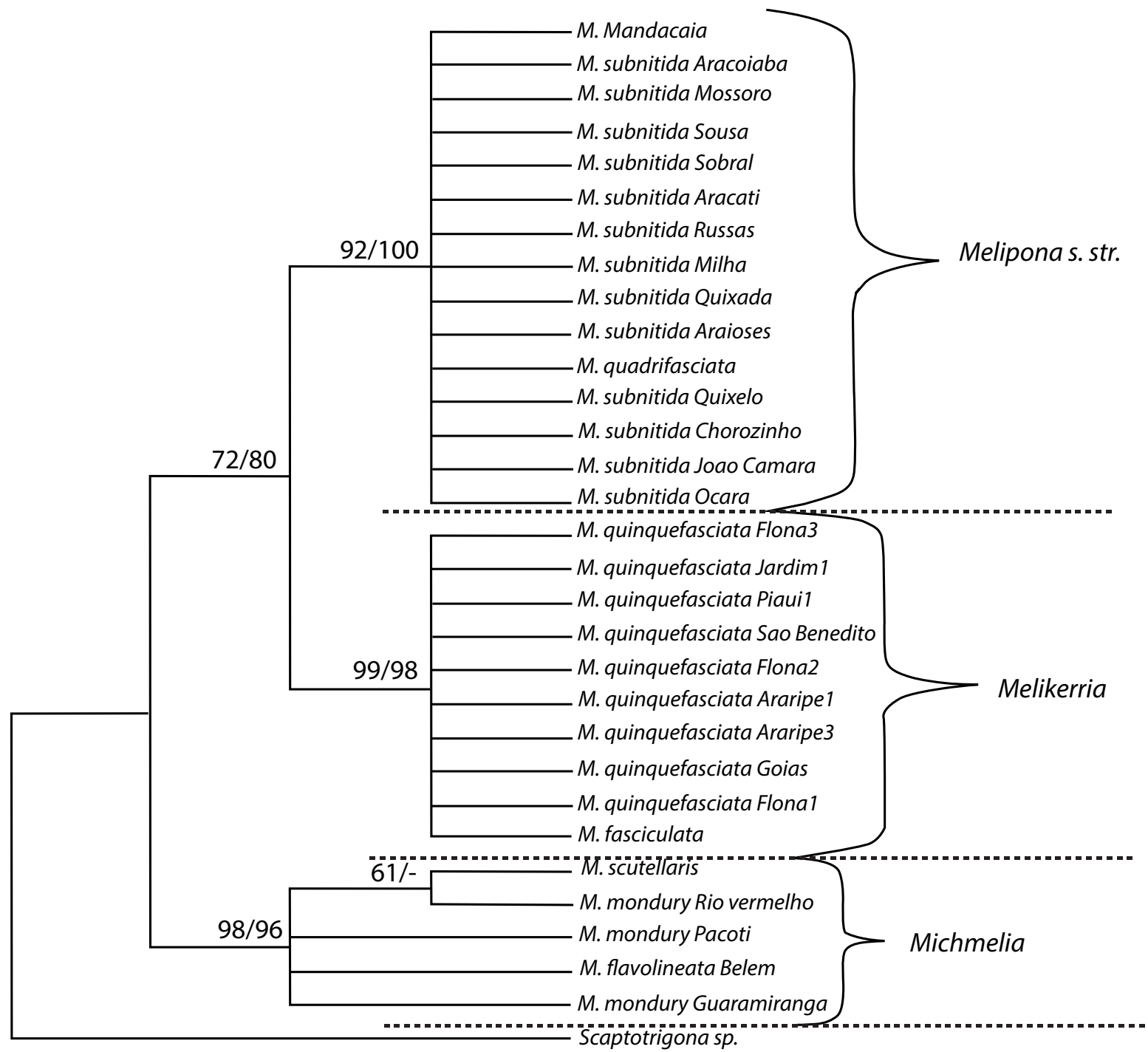

Figura 1 - Árvore consenso gerada pela análise de máxima parcimônia (MP) usando as sequências da região ITS1 do nrDNA para o táxon Melipona

Nota: Scaptotrigona sp. foi considerado o grupo externo. Os valores de bootstrap (1000 replicações) se encontram acima dos ramos para as análises de máxima parcimônia/máxima verossimilhança, respectivamente. 


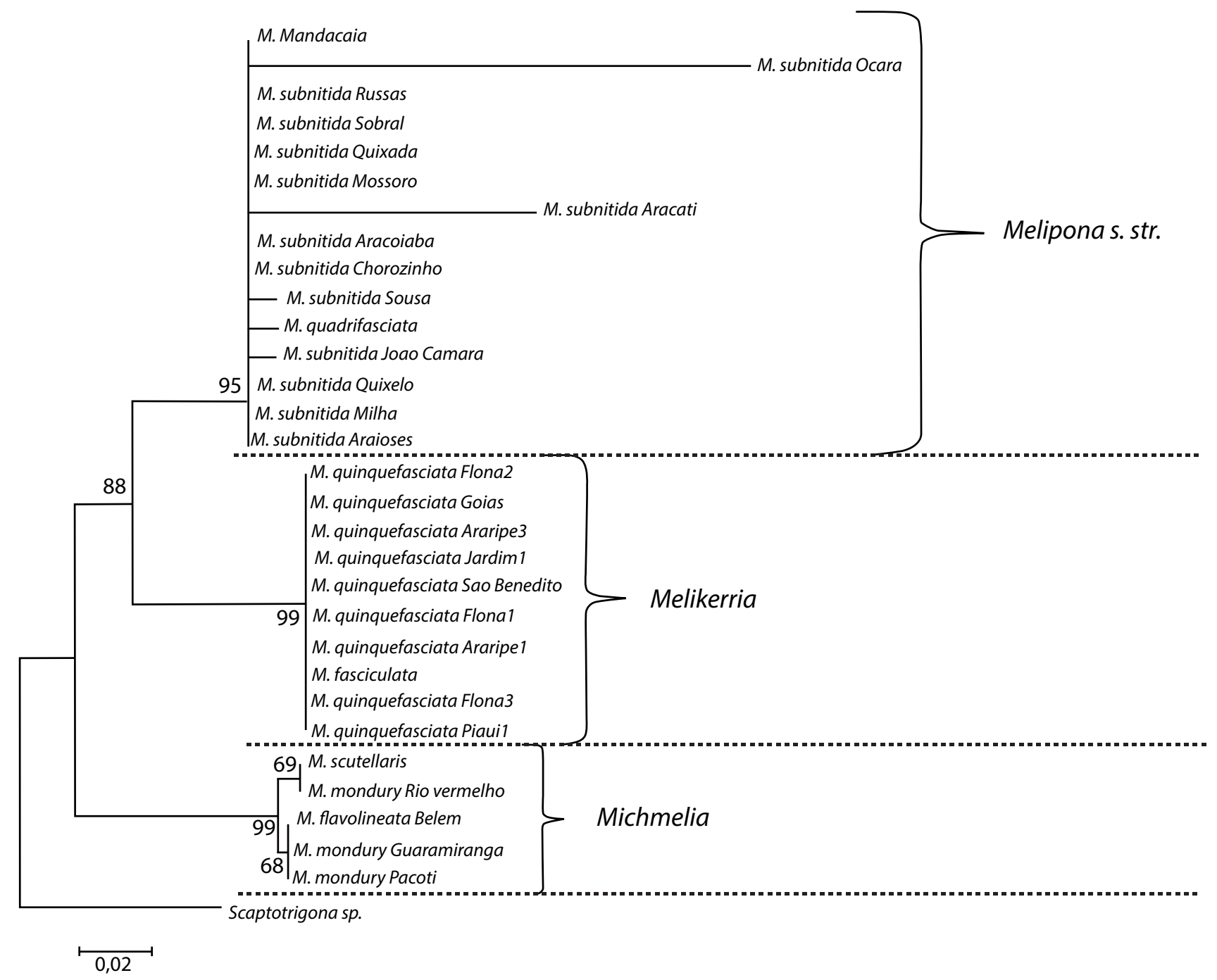

Figura 2 - Árvore original da análise do vizinho mais próximo (NJ) mostrando as relações filogenéticas no táxon Melipona baseada nas sequências da região ITS1 do nrDNA estudadas

Nota: Scaptotrigona sp. foi considerado o grupo externo. A matriz de distância foi calculada utilizando o modelo evolutivo de JC. Os números acima ou abaixo dos ramos indicam os valores de bootstrap com 1000 replicações. A escala da barra representa a distância genética entre os taxa. 
entre alguns espécimes de M. subnitida (Ocara versus Aracati) como demonstrado na Figura 2.

\section{Discussão}

Baseados no tamanho da região ITS1, FernandesSalomão et al. (2002), trabalhando com 11 espécies pertencentes ao gênero Melipona, distinguiram as espécies de Melipona em quatro grupos: 1) M. quadrifasciata, M. mandacaia, M. favosa, M. bicolor, $M$. quinquefasciata e M. compressipes, com 1430 pb; 2) M. scutellaris, M. capixaba e M. seminigra, com 1540 pb; 3) M. marginata com 1640 pb e 4) M. rufiventris com 1940 pb. Essa variação no tamanho da região ITS1 entre espécies do mesmo gênero já foi relatada para vários organismos, incluindo insetos (VON DER SCHULENBURG et al., 2001). Segundo FernandesSalomão et al. (2005), o comprimento variável da região ITS1 está relacionado principalmente a eventos de inserção e deleção (indels), além de sequências repetidas de um a quatro nucleotídeos.

0 sequenciamento da extremidade 3' da região ITS1, tanto das cinco amostras do gênero Melipona como do grupo externo, resultou em sequências de tamanhos inferiores às sequências previamente publicadas (FERNANDES-SALOMÃO et al., 2005; CRUZ et al., 2006; PEREIRA et al., 2009).

Essa variação no tamanho dos fragmentos deveu-se principalmente a fatores não identificados que interferiram no processo de sequenciamento. Esses fatores causaram principalmente uma interrupção prematura no sequenciamento de algumas amostras, que podem ser intrínsecos a cada espécie ou mesmo a cada amostra.

Apenas M. fasciculata e Scaptotrigona sp. apresentaram sequências com comprimentos superiores aos valores encontrados por outros autores, como Fernandes-Salomão et al. (2005); Cruz et al. (2006) e Pereira et al. (2009), cada uma com 511 pb e 566 pb, respectivamente. As demais amostras apresentaram sequências de tamanho variando desde $181 \mathrm{pb}$ em M. mondury - Rio Vermelho e M. mondury - Guaramiranga, até $421 \mathrm{pb}$ em M. flavolineata.

Resultados semelhantes foram encontrados por Fernandes-Salomão et al. (2005), que trabalharam com 11 espécies do gênero Melipona, cujo conteúdo $\mathrm{G}+\mathrm{C}$ da região ITS1 parcial variou de 49 a 54\%. Cruz et al. (2006) e Pereira et al. (2009), que trabalharam respectivamente com $M$. subnitida e $M$. quinquefasciata, também obtiveram conteúdo $\mathrm{G}+\mathrm{C}$ similar ao do presente trabalho, e mesmo que esses autores tenham trabalhado com variações intraespecíficas, seus conteúdos $\mathrm{G}+\mathrm{C}$, de sequências parciais da região ITS1 nrDNA, variaram de 53 a 56,2\% e 52,5 a $54,4 \%$, respectivamente.

Fernandes-Salomão et al. (2005), trabalhando com sequências completas da região ITS1 do nrDNA, observaram que a distância genética entre $M$. mandacaia e M. quadrifasciata anthidioides, ambas pertencentes ao subgênero Melipona, foi de apenas $1,4 \%$, enquanto que no presente trabalho, que utilizou sequências parciais, pôde-se observar um valor de 0,8\% (tamanho total de 1387 bp em M. mandacaia e 1391 bp em M. quadrifasciata). Os mesmos autores ainda observaram que quando tanto $M$. mandacaia quanto M. quadrifasciata anthidioides, foram comparadas com M. scutellaris (subgênero Michmelia), o percentual da distância genética aumentava para $25 \%$. No presente trabalho foi notada uma distância genética de 10,6\% entre $M$. mandacaia e $M$. scutellaris; e de $11,6 \%$ entre $M$. quadrifasciata e M. scutellaris. De acordo com Schneider (2007), nem todos os sítios evoluem na mesma taxa, ou seja, existe heterogeneidade para as taxas de substituições ao longo dos sítios. Portanto, esses resultados sugerem que o fragmento da região ITS1 sequenciado no presente trabalho representa uma zona com menores percentuais de mudanças nucleotídicas, ou seja, mais conservado quando comparado com a região ITS1 como um todo.

Além disso, observou-se a disposição do grupo 3 (representado pelas abelhas do subgênero Michmelia) em um ramo mais basal, diferindo dos achados de Fernandes-Salomão et al. (2005) e de Rasmussen e Cameron (2010), que apontaram esse subgênero em ramos mais apicais. A filogenia obtida no presente trabalho corrobora com a classificação em subgêneros, baseados tanto em caracteres morfológicos, propostos por Moure (1992) e Silveira et al. (2002), como em dados moleculares já relatados previamente (FERNANDES-SALOMÃO et al., 2005; RAMÍREZ et al., 2010; RASMUSSEN; CAMERON, 2010). 


\section{Conclusão}

Mesmo considerando a necessidade de ampliação do número de amostras para uma futura revisão taxonômica do gênero Melipona, os dados moleculares gerados no presente trabalho foram capazes de sugerir a validade da atual classificação do gênero Melipona em pelo menos três subgêneros (Melipona s. str., Melikerria e Michmelia) e demonstrar a utilidade da região ITS1 do nrDNA para resolver relações de parentesco infragenéricas em Meliponina.

\section{Referências}

ARMBRUSTER, G. F. J.; KORTE, A. Genomic nucleotide variation in the ITS1 rDNA spacer of land snails. Journal of Molluscan Studies, v. 72, n. 2, p. 211-213, 2006. doi: 10.1093/mollus/eyi056.

BECERRA, J. X.; VENABLE, D. L. Nuclear ribosomal DNA phylogeny and ITS implications for evolutionary trends in Mexican Bursera (Burseraceae). American Journal of Botany, v. 86, n. 7, p. 1047-1057, 1999. PMid:10406728.

CRUZ, D. O. et al. Intraspecific variation in the first internal transcribed spacer of the nuclear ribosomal DNA in Melipona subnitida (Hymenoptera, Apidae), an endemic stingless bee from northeastern Brazil. Apidologie, v. 37, n. 3, p. 376-386, 2006. doi:10.1051/ apido:2006003.

EWING, B.; GREEN, P. Base-calling of automated sequencer traces using Phred. II. Error probabilities. Genome Research, v. 8, n. 3, p. 186-194, 1998. PMid:9521922.

EWING, B. et al. Base-calling of automated sequencer traces using Phred. I. Accuracy assessment. Genome Research, v. 8, n. 3, p. 175-185, 1998. PMid:9521921.

FERNANDES-SALOMÃO, T. M. et al. Mitochondrial and nuclear DNA characterization in the Melipona species (Hymenoptera, Meliponini) by RFLP analysis. Hereditas, v. 137, n. 3, p. 229-233, 2002. doi:10.1034/j.1601-5223.2002.01685.x.

FERNANDES-SALOMÃO, T. M. et al. The first internal transcribed spacer (ITS-1) of Melipona species (Hymenoptera, Apidae, Meliponini): characterization and phylogenetic analysis. Insectes Sociaux, v. 52, n. 1, p. 11-18, 2005. doi:10.1007/s00040-004-0767-8.
FOSTER, G. R.; TWELL, D. Plant gene isolation: principles and practice. West Sussex: John Wiley, 1996.

GORDON, D. et al. Consed: a graphical tool for sequence finishing. Genome Research, v. 8, n. 3, p. 195-202, 1998. PMid:9521923.

JOBES, D. V.; THIEN, L. B. A conserved motif in the 5,8S ribosomal RNA (rRNA) gene is a useful diagnostic marker for plant internal transcribed spacer (ITS) sequences. Plant Molecular Biology Reporter, v. 15, n. 4, p. 326334, 1997. doi:10.1023/A:1007462330699.

JUDD, W. S. et al. An overview of green plant phylogeny. In: JUDD, W. S. (Ed.). Plant systematics: a phylogenetic approach. Sunderland, UK: Sinauer Associates Inc., 2008. p. 153-184.

JUKES, T.; CANTOR, C. Evolution of protein molecules. In: MUNRO, H. (Ed.). Mammalian Protein Metabolism. New York: Academic Press, 1969. p. 21-123.

MELO, G. A. R. Notas sobre meliponíneos neotropicais, com a descrição de três novas espécies (Hymenoptera, Apidae). In: MELO, G. A. R.; SANTOS, I. A. (Ed.). Apoidea neotropica: homenagem aos 90 anos de Jesus Santiago Moure. Criciúma: UNESC, 2003. p. 85-91.

MICHENER, C. D. The bees of the world. 2. ed. Baltimore: The Johns Hopkins University Press, 2007.

MIYAKI, C. Y.; RUSSO, C. A. M.; PEREIRA, S. L. Reconstrução filogenética: introdução e o método da parcimônia. In: MATIOLI, S. R. (Ed.). Biologia Molecular e Evolução. Ribeirão Preto: Holos Editora, 2001. p. 97-107.

MOURE, J. S. Melikerria e Eomelipona, dois subgêneros novos em Melipona Illiger, 1806 (Hymenoptera, Apidae). In: CRUZ-LANDIM, C.; CHAUD-NETTO, J. (Ed.). Anais do Encontro Brasileiro de Biologia de Abelhas e Outros Insetos Sociais/Naturalia. Número especial em homenagem aos 70 anos do Prof. Kerr. São Paulo: UNESP, 1992. p. 32-38.

NEI, M.; KUMAR, S. Molecular Evolution and Phylogenetics. New York: Oxford University Press, 2000.

PEREIRA, J. O. et al. Genetic variability in Melipona quinquefasciata (Hymenoptera, Apidae, Meliponini) from northeastern Brazil determined using the first internal transcribed spacer (ITS1). Genetics and Molecular Research, v. 8, n. 2, p. 641-648, 2009. PMid:19554762. 
PEREIRA, S. L. et al. Reconstrução filogenética: métodos probabilísticos. In: MATIOLI, S. R. (Ed.). Biologia molecular e evolução. Ribeirão Preto: Holos, 2001. p. 117-129.

POSADA, D.; CRANDALL, K. A. ModelTest: Testing the model of DNA substitution. Bioinformatics, v. 14, n. 9, p. 817-818, 1998. doi:10.1093/ bioinformatics/14.9.817.

RAMÍREZ, S. R. et al. A molecular phylogeny of the stingless bee genus Melipona (Hymenoptera: Apidae). Molecular Phylogenetics and Evolution, v. 56, n. 2, p. 519-525, 2010. doi:10.1016/j.ympev.2010.04.026.

RASMUSSEN, C.; CAMERON, S. A. Global stingless bee phylogeny supports ancient divergence, vicariance, and long distance dispersal. Biological Journal of the Linnean Society, v. 99, n. 1, p. 206-232, 2010. doi:10.1111/j.1095-8312.2009.01341.x.

SAMBROOK, J.; RUSSEL, D. W. Molecular cloning: a laboratory manual. 3. ed. New York, NY: Cold Spring Harbor Laboratory Press, 2001.

SCHNEIDER, H. Métodos de análise filogenética: um guia prático. 3. ed. Ribeirão Preto: Holos, 2007.

SILVEIRA, F. A. et al. Abelhas brasileiras: sistemática e identificação. Belo Horizonte: IDM Composição e Arte, 2002.
SWOFFORD, D. L. PAUP*: phylogenetic analysis using parsimony (and other methods) - version 4.0 beta. Sunderland: Sinauer Associates, 1998.

TAMURA, K. et al. MEGA4: molecular evolutionary genetics analysis (MEGA) Software Version 4.0. Molecular Biology and Evolution, v. 24, n. 8, p. 1596-1599, 2007. PMid:17488738.

THOMPSON, J. D. et al. The ClustalX windows interface: flexible strategies for multiple sequence alignment aided by quality analysis tools. Nucleic Acids Research, v. 25, n. 24, p. 4876-4882, 1997. PMid:9396791.

VELTHUIS, H. H. W. et al. The conservative egg of the genus Melipona and its consequences for speciation. In: MELO, G. A. R.; SANTOS, I. A. (Ed.). Apoidea neotropica: homenagem aos 90 anos de Jesus Santiago Moure. Criciúma: UNESC, 2003. p. 171-176.

VON DER SCHULENBURG, J. H. et al. Extreme length and length variation in the first ribosomal internal transcribed spacer of ladybird beetles (Coleoptera: Coccinellidae). Molecular Biology and Evolution, v. 18, n. 4, p. 648-660, 2001. PMid:11264417.

ZHANG, Z. et al. A greedy algorithm for aligning DNA sequences. Journal of Computational Biology, v. 7, n. 1-2, p. 203-14, 2000. doi:10.1089/10665270050081478.

Recebido em: 10/12/2013

Received in: 12/10/2013

Aprovado em: 22/03/2015 Approved in: 03/22/2015 